\title{
Macrosomia, transient neonatal hypoglycemia, and monogenic diabetes in a family with heterozygous mutation R154X of HNF4A gene
}

Congenital hyperinsulinemic hypoglycemia $(\mathrm{CHI})$ is a potentially life-threatening condition which is often caused by loss-of-function mutations in ABCC8 and KCNJ11 genes, that encode for the ATP-sensitive potassium channel of the pancreatic $\beta$ cell. Recently, it has been shown that in families with monogenic diabetes due to genetic defects of the transcription factor HNF4A [known as Maturity Onset Diabetes of the Young type 1 (MODY1)] mutation carriers can present neonatal hypoglycemia and macrosomia (1). Here we report about a girl born large for gestational age, who showed severe neonatal hypoglycemia (day 1 of life) treated with glucose infusion (Table 1). She had a second hypoglycemic episode at day 9, treated again with glucose infusion for 2 days. Her younger sister, who was delivered by cesarean section because of macrosomia and polyhydramnios at 34 weeks of gestation, also presented with mild, transient neonatal hypoglycemia. Both were referred to us for molecular genetic screening. Family history disclosed early-onset Type 2 diabetes in the mother and in the maternal grandfather. In particular, the mother had been diagnosed with gestational diabetes - treated with insulin - during her second pregnancy (35 yr of age) and, after a year free of therapy, started on oral hypoglycemic agents. These data combined prompted us to screen directly the HNF4A gene in this family. We identified a C>T substitution at position 460 (c.460C>T), resulting in the already described mutation arginine $\rightarrow$ stop at codon 154 (p.R154X) (Table 1) in the proband, her sister, and her mother. DNA of maternal grandfather, deceased, was not available. The proband, now almost $15 \mathrm{yr}$ old (pubertal stage: $\mathrm{Ph} 5, \mathrm{~B} 5)$, and a bit overweight, has shown at the last visit above normal glycated hemoglobin value compatible with recently proposed criteria for diagnosis of diabetes (2). This finding is in line with what is usually seen in patients with heterozygous mutations of HNF4A gene or TCF1/HNF1A (so-called MODY 3), who present with diabetes at adolescence or as young adults.
Mutations of HNF4A have been associated to both transient $(1,3,4)$ or persistent, diazoxide-responsive form of $\mathrm{CHI}(1,5,6)$, with no apparent correlation between mutation type and clinical outcome of hypoglycemia (i.e. transient vs persistent) (1). Mutation HNF4A/R154X has already been described in patients with MODY 1 (7); this is the first time, however, that it has been associated with macrosomia and neonatal hypoglycemia. It has to be taken into account, however, that prematurity per se is also considered a risk factor for neonatal hypoglycemia and that the low plasma glucose found in a single occasion in proband's sister, born at the $34^{\text {th }}$ week of gestation, may also be due to this fact. Dominant heterozygous mutations of ABCC8 and KCNJ11 genes causing $\mathrm{CHI}$ may also be rarely associated with Type 2 diabetes in adult family members carrying the genetic defect (8). Thus, families with the aforementioned clinical features may be challenging in terms of molecular genetic diagnosis. In summary, we confirm that the presence of macrosomia and neonatal hypoglycemia in a family with history of diabetes is a strong indicator of a mutation in the HNF4A gene and suggest that in cases analogous to the one reported here, molecular genetic screening of this gene should be performed as first step.

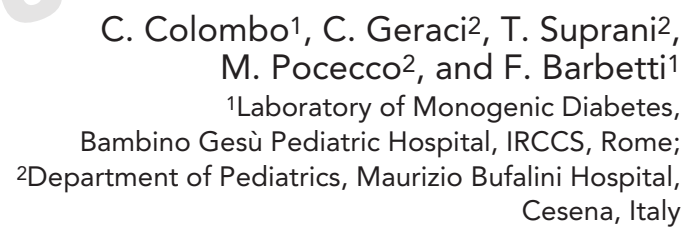

๑2011, Editrice Kurtis

Accepted January 17, 2011

Table 1 - Clinical features of family members carrying the HNF4A/R154X mutation.

\begin{tabular}{|c|c|c|c|}
\hline & Proband & Sister & Mother \\
\hline Mutation HNF4A/R154X & $\mathrm{n} / \mathrm{m}$ & $\mathrm{n} / \mathrm{m}$ & $\mathrm{n} / \mathrm{m}$ \\
\hline Birth weight (g), weeks of gestation, percentile & $4220,40,>>97^{\circ}$ & $2620,34,90^{\circ}$ & n.a. \\
\hline Plasma glucose at birth (mg/dl) & $\begin{array}{l}17 \text { (day } 1 \text { of life) } \\
33 \text { (day } 9 \text { of life) }\end{array}$ & 31 (day 1 of life) & n.a. \\
\hline Current age & $14 \mathrm{yr}, 10 \mathrm{~m}$ & $10 \mathrm{yr}, 6 \mathrm{~m}$ & 45 \\
\hline Current BMI & 28.8 & 20 & 25.9 \\
\hline Current $\mathrm{HbA}_{1 \mathrm{c}} \%$ (mmol) & $7.3(56)$ & $5.3(34)$ & $8.2(66)$ \\
\hline Current therapy & None & None & Glargine $8 \mathrm{U} / \mathrm{d}+\mathrm{OHA}$ \\
\hline
\end{tabular}

n/m: normal/mutant; BMI: body mass index; OHA: oral hypoglycemic agents; $\mathrm{HbA}_{1 \mathrm{c}}$ : glycated hemoglobin. 


\section{REFERENCES}

1. Pearson ER, Boj SF, Steele AM, et al. Macrosomia and hyperinsulinaemic hypoglycaemia in patients with heterozygous mutations in the HNF4a gene. PLoS Med 2007, 4: e118.

2. International Expert Committee. International Expert Committee report on the role of the $\mathrm{A} 1 \mathrm{C}$ assay in the diagnosis of diabetes. Diabetes Care 2009, 32: 1327-34.

3. Fajans SS, Bell GI. Macrosomia and neonatal hypoglycemia in RW pedigree subjects with a mutation (Q268X) in the gene encoding hepatocyte nuclear factor 4a (HNF4a). Diabetologia 2007, 50: 2600-1.

4. Conn JJ, Simm PJ, Oats JJN, et al. Neonatal hyperinsulinaemic hypoglycaemia and monogenic diabetes due to a heterozygous mutation of the HNF4a gene. Aust N Z J Obstet Gynaecol 2009, 49: 328-30.
5. Kapoor RR, Locke J, Colclough K, et al. Persistent hyperinsulinemic hypoglicemia and maturity-onset diabetes of the young due to heterozygous HNF4a mutations. Diabetes 2008, 57: 1659-63.

6. Flanagan SE, Kapoor RR, Mali G, et al. Diazoxide-responsive hyperinsulinemic hypoglycemia caused by HNF4A gene mutations. Eur J Endocrinol 2010, 162: 987-92.

7. Lindner $\mathrm{T}$, Gragnoli $\mathrm{C}$, Furuta $\mathrm{H}$, et al. Hepatic function in a family with a nonsense mutation (R154X) in the hepatocyte nuclear factor4alpha/MODY1 gene. J Clin Invest 1997, 100: 1400-5.

8. Pinney SE, MacMullen C, Becker S, et al. Clinical characteristics and biochemical mechanism of congenital hyperinsulinism associated with dominant KATP channel mutations. J Clin Invest 2008, 118: $2877-86$. 